\title{
A retrospective review of clinical ethics consultations requested by nurses for oncology patients
}

\author{
Colleen M. Gallagher, Megan Ball Neel, Claudia R. Sotomayor \\ The University of Texas MD Anderson Cancer Center
}

\begin{abstract}
Background: With growing importance of clinical ethics in daily nursing practice, and the increasing occurrence and utilization of ethics consultation nationwide, awareness about the motives behind consults is vital to enhancing patient care. Aim: To determine the predominant requests for ethics consultation from nurses in a cancer setting. Design: This is a retrospective data review of the ethics consultations recorded in the clinical ethics consultation database. The data reviewed consist of the ethics consults requested by nurses from records in the database of consultations conducted from January 1, 2008 through July 31, 2013. Findings: The predominant reason for requesting an ethics consult was the level of appropriate care with a total of 27 consults $(28 \%)$. Within this topic, there were ten consults about the shift from curative care to palliative care, 13 about code status, 2 about general appropriate level of care and 2 regarding hospice. Discussion: The data show that the nurses at this hospital had similar concerns as other nurses in the literature in that there were several requests for concerns regarding code status, informed consent, and appropriate treatment, including the decision to withhold or withdraw life-sustaining therapies. Conclusion: Improving access to ethics consultation services access and the ethics education for nursing staff are necessary steps to improve confidence among them to engage more often with clinical ethics consultation.
\end{abstract}

Keywords: clinical ethics consultation; nursing ethics

\section{Introduction}

In 1982, only 1\% of hospitals in the United States of America had established a form of ethics consultation, but by 1988 , this number had increased to $67 \%$ (Fleetwood et al. 1989). In 1992, the Joint Commission on the Accreditation of Health Care Organizations released a mandate that required that all American hospitals establish a "mechanism" for hospital personnel to consider and educate its constituents on ethical issues in patient care, and by the year 2000 it was estimated that over $95 \%$ of community hospitals had established a clinical ethics committee (Caulfield 2007). Although these committees remain largely underutilized with a national average in the United States of 3 to 8 consults per year (Coutrwright et al. 2014), efforts are being made to standardize the ethics consultation practice, which is increasing the awareness and the utilization of this service (Tarzian and ASBH Core Competencies Update Task Force 2013).

It is noticeable that nursing staff contribute to a low proportion of these consults. (Cohen \& Erickson, 2006; Grady et al., 2008; Oberle \& Hughes, 2001; Woods, 2005; Zuzelo, 2007). This is intriguing because nurses represent the largest health care profession in the United States (Redman \& Fry, 2000). It is well documented that nurses are confronted with ethical dilemmas on a daily basis that may relate to inadequate resources, patient care concerns, or professional Copyright (C) 2018 Colleen Mary Gallagher doi: $10.18686 /$ jn.v7i1.137

This is an open-access article distributed under the terms of the Creative Commons Attribution Unported License

(http://creativecommons.org/licenses/by-nc/4.0/), which permits unrestricted use, distribution, and reproduction in any medium, provided the original work is properly cited. 
conflict (Zuzelo, 2007). A recent study showed that about $20 \%$ of the requests for ethics consultation came from nurses, and that requests fell into several broad topic-oriented categories such as: Plan of Care, End of Life, Goals-Values-Preferences Questions, Nurse-Physician Issues, Honoring Patient Preferences, Futility, etc.

With growing importance of clinical ethics in daily nursing practice, and the increasing occurrence and utilization of ethics consultation nationwide, awareness about the reasons behind consults is vital to enhancing patient care. Knowing that Cancer medicine provides a unique opportunity for nurse and patient interactions that involve ethical issues, the purpose of this study is to determine the predominant requests for ethics consultation from nurses in a cancer care setting.

\section{Design and Methods}

This is a retrospective data review of the ethics consultations recorded in the clinical ethics consultation database. The data reviewed consist of the consults requested by nurses from records in the database as of August 31, 2013 (consultations conducted from January 1, 2008 through July 31, 2013).

Data was collected from the Clinical Ethics Database at a large cancer hospital in Southeast Texas. The hospital has 661 inpatient beds and about 135,000 people received treatment from the hospital through inpatient admissions or outpatient clinic visits, treatments, or procedures in 2016 (MD Anderson, 2017) The nurses who requested ethics consultations included in this study are Registered Nurses (RNs), Advanced Practice Registered Nurses (APRNs), Clinical Nurse Specialist (CNS), and other nurses in the healthcare team. For the purposes of this paper, only two categories were used -APRN and RN. The term "APRN" includes nurses who practice with that license. The RN group is comprised of the other nurses. The data includes Ethics Consultation Service (ECS) requests received from nurses to intervene in a situation. The data was analyzed to determine the reasons causing nurses to request, the variability of requests, the frequency of certain types of requests and other related information that would be valuable in understanding what the concerns nurses find important when requesting and ethics consultation.

The model for ethics consultation at this hospital may vary from the service at other hospitals. The ethicists observe patient care and make recommendations during clinical rounds in an attempt to address ethical concerns in a timely manner. Additionally, the ethics team meets with nurses once a month to discuss ethical concerns through nursing ethics rounds. This proactive approach leads to more face-to-face recommendations by ethics team members, although these recommendations are not included in the request for consultation data analyzed here. The writers do recognize that this approach may lead to different types of consult requests than some readers may experience in their own clinical settings.

\section{Results}

From January 1, 2008 through July 31, 2013 there were 427 consults requests, of which 91 were made by nurses (22.31\%). There were 78 inpatient consults and 13 outpatient consults. Of the 91, 47.52\% were requested by RNs and $44.48 \%$ by APRNs. The service with the most consultations was the ICU with a total of $16(14 \%)$, followed by lymphoma with 11 (12.08\%) and Stem Cell Transplant with 8 (8.78\%) (Table 1). 


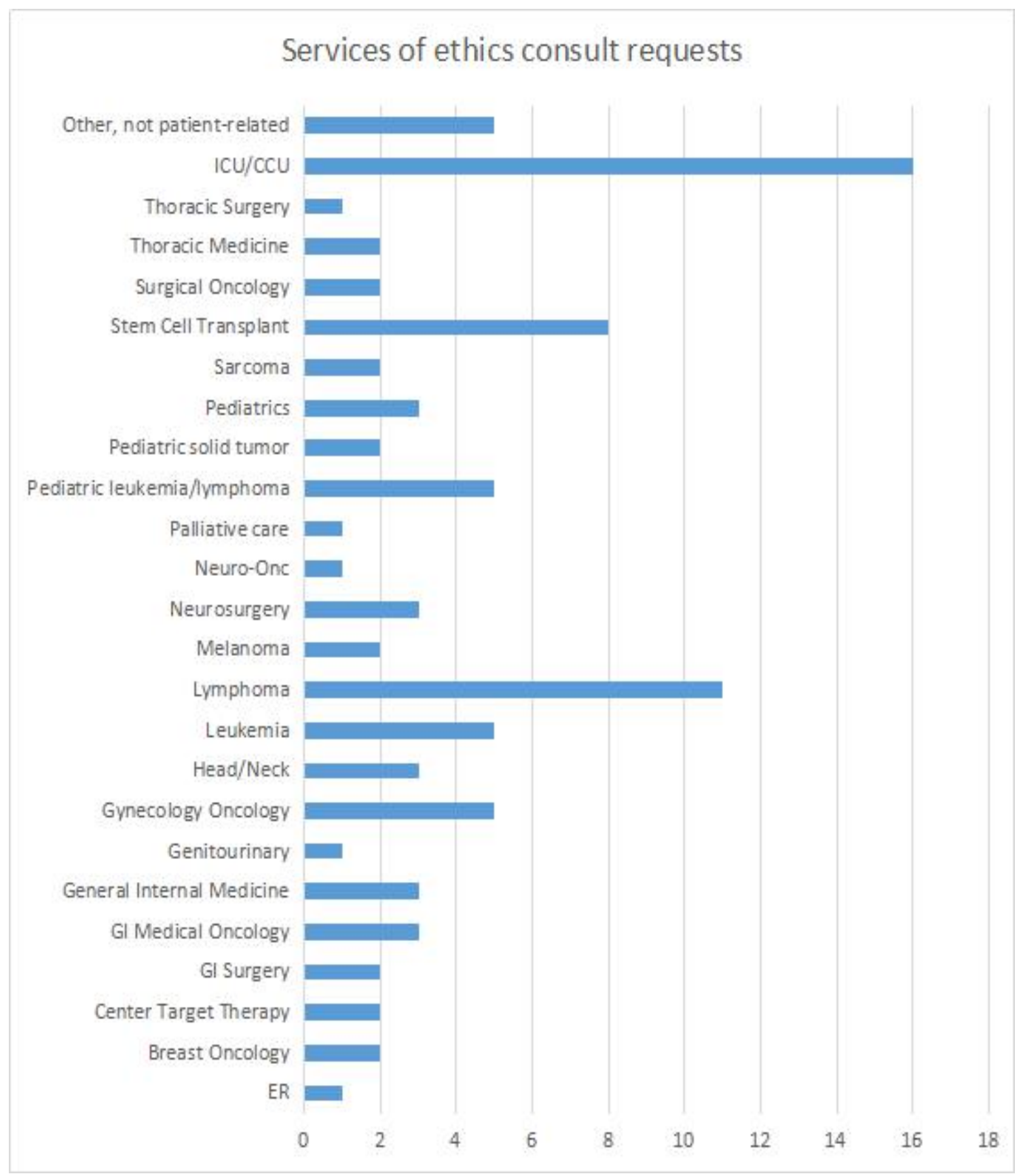

Table1. Services of ethics consult requests. CCU 6; lymphoma 11; stem cell transplant 8; breast oncology 2; center target therapy 2; GI surgery 2; GI medical oncology 3; general internal medicine 3; genitourinary 1; gynecology oncology 5; head and neck 3; leukemia 5; melanoma 2; neurosurgery 3; neuro-oncology 1; palliative care 1; pediatric leukemia 5; pediatric solid tumor 2; pediatrics 3; sarcoma 2; surgical oncology 2; thoracic medicine 2; thoracic surgery 1; other non-patient related 5.

Comparing the services that originated the requests with the type of nurse, the data showed that APRNs requested more consults in some areas such as ICU, with a total of 10 requests and lymphoma with a total of 7 requests. There were some services where only RNs requested consults such as GI surgery, melanoma, palliative care, pediatrics, sarcoma, thoracic medicine and thoracic surgery, and center target (see Table 2.) 


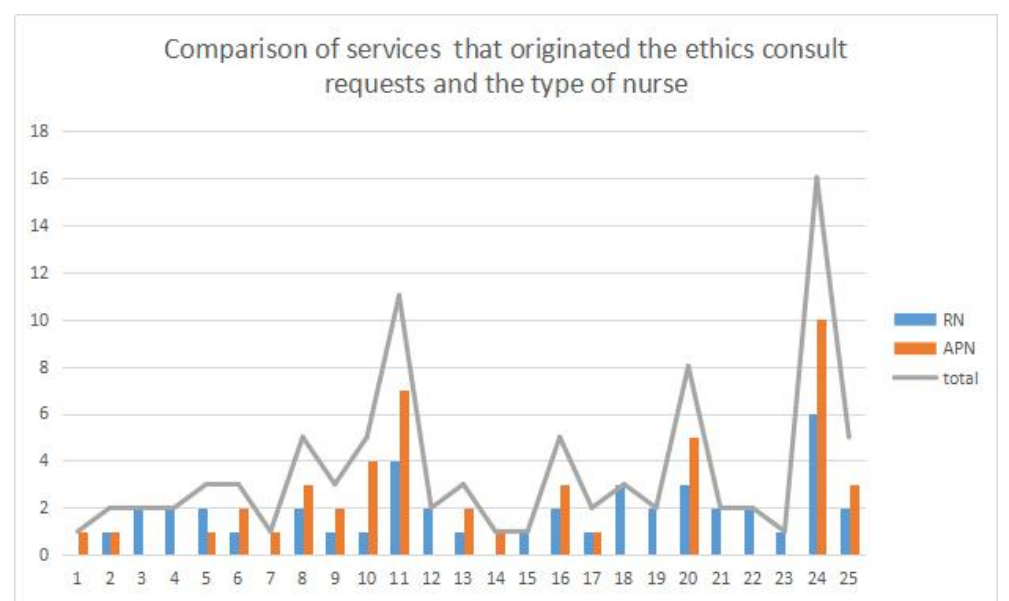

Table2. Comparison of services that originated the ethics consult requests and the type of nurse. 1. ER (RN0- APRN1), 2. Breast oncology (RN 1-APRN 1), 3. Center target therapy (RN2-APRN0), 4. GI surgery (RN2- APRN 0), 5. GI medical oncology (RN2-APRN 1), 6. General internal medicine (RN 1- PRN 2), 7. Genitourinary (RN 0-APRN 1), 8. Gynecology oncology (RN 2-APRN3), 9. Head and Neck (RN1-APRN 2), 10. Leukemia (RN 1-APRN 4), 11. Lymphoma (RN 4-APRN 7), 12. Melanoma (RN 2-APRN 0), 13. Neurosurgery (RN 1-APRN 2), 14. Neuro-oncology (RN 0-APRN 1), 15. Palliative care (RN 1-APRN 0), 16. Pediatric leukemia/lymphoma (RN 1-APRN3), 17. Pediatric solid tumor (RN 1-APRN 1), 18. Pediatrics (RN 3- APRN 0); 19. Sarcoma (RN 2-APRN 0), 20. Stem cell transplant (RN 3-APRN 5), 21. Surgical oncology (RN 2-APRN 0), 22. Thoracic medicine (RN 2-APRN 0), 23. Thoracic surgery (RN 1-APRN 0), 24. CCU (RN 6- APRN 10), 25. Other non-patient related (RN 2-APRN3)

The predominant reason for consult was regarding the level of appropriate care with a total of 27 consults (28\%). Within this category, there were ten consults about the shift from curative care to palliative care, 13 about code status, 2 about general appropriate level of care and 2 regarding hospice. The second reason for consult request was regarding informed consent $(12 \%)$, where 6 of them were related to treatment, 4 to research, and 1 to surrogate consenting. Difficult discharges and medical futility were also among the most common reasons for consults with $9 \%$ and $7 \%$ respectively (Table 2).

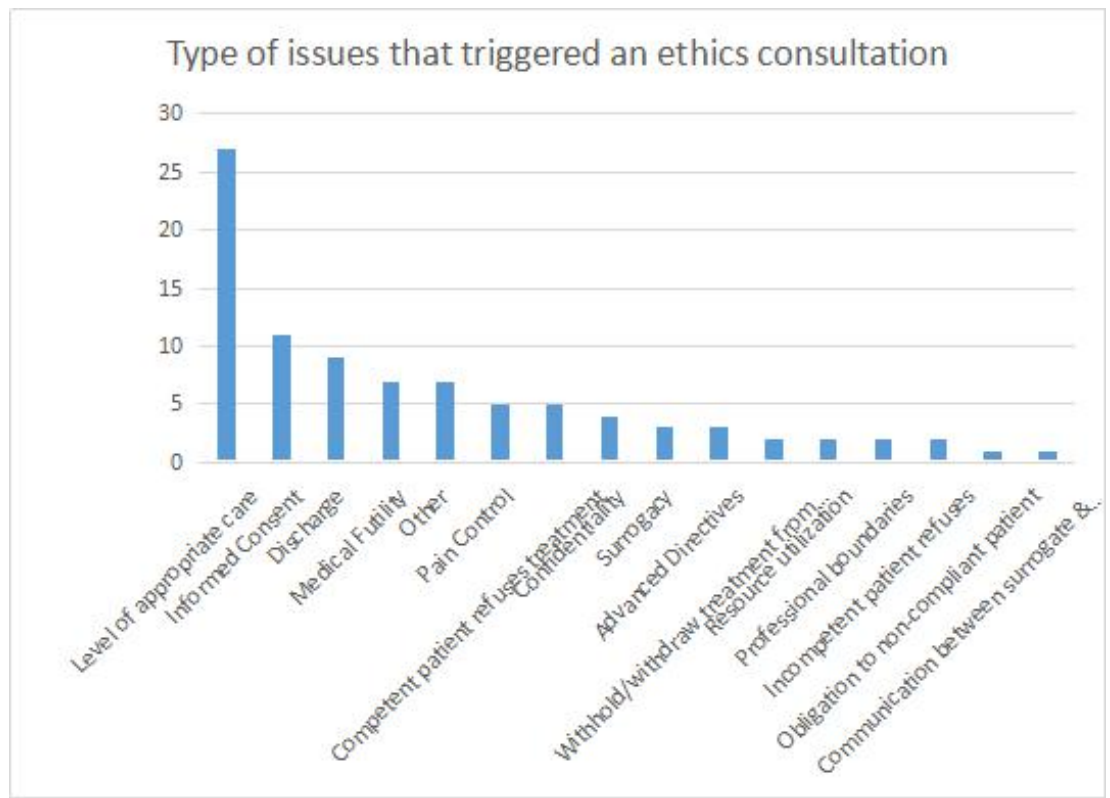

Table 2. Type of issues that triggered an ethics consultation. Level of appropriate care 27, Informed consent 11, difficult discharge 9 , medical futility 7, Pain control 5, competent patient refuses treatment 5 , confidentiality 4, surrogacy 3 , advanced directives 3 , withhold/withdraw treatment for incompetent patient 2 , resource utilization 2 , professional boundaries 2 , incompetent patient refuses treatment 2, obligation to non-compliant patient 1, communication between surrogate and patient with staff 1 . 
Comparing both RNs and APRNs regarding the most common types of issues that triggered a consultation, it is shown that both RNs and APRNs call more often for issues regarding level of appropriate care, but APRNs are more focused on that particular issue. RNs had a more diverse type of consultations including informed consent issues, medical futility, and pain control, among others (Table 3).

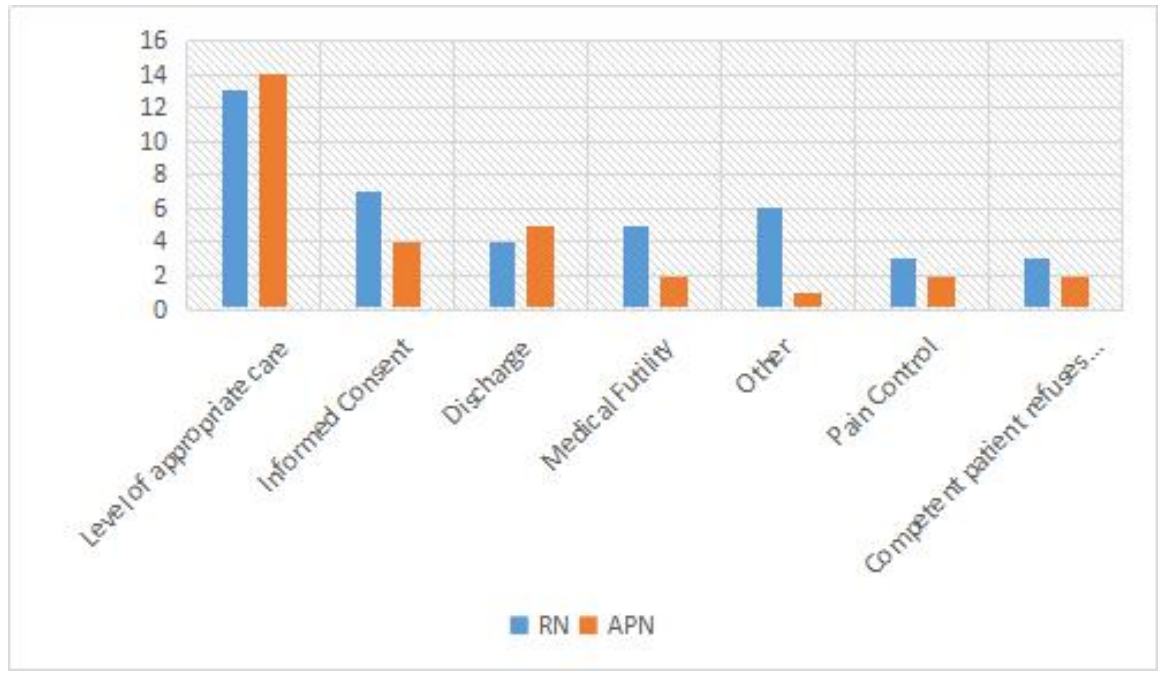

Table 3. Comparison of issues between RNs and APNs. Level of appropriate care RN 13 APN 14. Informed consent RNs 7, APN 4; discharge RNs 4, APNs 5; medical futility RNs 5, APNs 2; other RNs 6, APN 1; pain control RNs 3, APNs 2; competent patient refuses treatment RNs 3, APNs 2 .

\section{Discussion}

The overall data showed that many of the ethics consult requests were to assist the clinical staff with some form of mediation, as is typical of many ethics consults (Fox et al., 2007; Schlairet et al., 2012). This mediation was sometimes in the form of discussing the role of the surrogate decision-maker in honoring the patient's wishes, or in the form of being present at a family meeting to ensure that the messages of the team were clearly understood by the patient. The data did show that the nurses at this hospital had similar concerns as other nurses in the literature in that there were several requests for concerns regarding code status, informed consent, and appropriate treatment, including the decision to withhold or withdraw life-sustaining therapies (Nilson et al., 2008; Oberle \& Hughes, 2001; Schneiderman et al., 2003; Zuzelo, 2007). It is not surprising that the largest portion of the ethical consult requests involved the end of life discussions, such as the level of appropriate care or the shift from curative to palliative treatment. These difficult scenarios often lead to discord within clinical teams or between the teams and the patient/family and are noted in many studies (Nilson et al., 2008; Schneiderman et al., 2003). There were other ethical concerns found in this setting that have not been presented at a high frequency in other studies, such as appropriate discharge of patients.

In this hospital, ethicists participate in clinical rounds regularly in different services, and daily in the Critical Care Unit (CCU). It is common then that the first service that typically contacts our department is the CCU. This may be related also to the fact that the majority of these clinicians and their patients encounter end-of-life situations that often require the assistance of trained ethicists to facilitate in difficult scenarios (Nilson et al., 2008). In an oncology setting, the Stem Cell Transplant (SCT) service is another at-risk group. Due to this known risk, we wanted to determine whether or not a specific clinical service or unit was more prone to making ethics requests. We reviewed both the clinical service (such as SCT or pediatrics) and the clinical unit from which the request was made (such as CCU or the outpatient team) to identify areas which may need additional support. Not surprisingly, there were many consults for 
patients in known at-risk group such as the CCU with a total of $16(14 \%)$. The few outliers to this were the SCT group, often patients who have diagnosis of leukemia and lymphoma - two other clinical services with high rates of consult requests. While lymphoma and leukemia are some of the more frequently diagnosed cancers (American Cancer Society, 2014), it is interesting that these two services would call at a higher rate than the nurses in other departments who also have a large number of patients, such as Breast Oncology or the Gastrointestinal Oncology teams. Many of the consults did come from services where the ethics team members do not participate in clinical rounds. Whether this is as a result of promotion of the ECS throughout the hospital, an environment that allows for consults to be made, or the severity of a particular consult is unknown and not studied here.

We expected that the RN group would request consults at a lower rate that the APRN group, similar to what is seen in the literature (Doane et al., 2004; Grady et al., 2008). Surprisingly, the RN group had slightly more consults than the APRN group, although the reason for this difference is unknown. It may be attributed to factors not studied here, such as the nurses' individual education, the education provided at the hospital, or other environmental factors such as the face-to-face interactions the ethics team has with the clinical team members. The types of consults requested did not vary to a discernable degree, which is also interesting.

\section{Conclusion}

The results of this study are consistent with similar studies done in other institutions (Nilson et al., 2008; Oberle \& Hughes, 2001; Schneiderman et al., 2003; Zuzelo, 2007). There are some possible reasons behind the low percentage (22\%) of ethics consults requests done by nurses: 1) lack of confidence from the nursing staff to call for an ethics consultation. Historically, nurses in the hospital setting have chosen not to seek ethics consultations due to real or perceived barriers within the workplace (Cohen \& Erickson, 2006; Grady et al., 2008; Oberle \& Hughes, 2001; Woods, 2005; Zuzelo, 2007); and 2) nurses may feel that they do not have the time to address such concerns, it will be a hassle, the information given will not be confidential or that it could lead to conflict within the team members (Cohen \& Erickson, 2006; Grady et al., 2008)

Nurses need to feel comfortable asking for ethics consultations, and this is often achieved through education and familiarity with the ethics service (Grady et al., 2008; Kalaitzidis \& Schmitz, 2012). Even if nurses have not received ethics-specific education in their training program, it may be possible to train them within the institution through group meetings and interactions with the ethics team. A lot of this will depend on the clinical environment, and the nursing leaders in the workplace need to foster ethical behaviors (Kearney \& Penque, 2012). By creating a work environment that will allow nurses to request assistance from the ECS without fear of retaliation, the nurses can help to avoid medical errors created as a result of a lack of communication (Kearney \& Penque, 2012).

\section{Reference}

1. Fleetwood J, Arnold R, Baron R, 1989, Giving answers or raising questions? The problematic committees. Journal of Medical Ethics, 15(3): 137-142. doi: 10.1136/jme.15.3.137

2. Caulfield S, 2007, Health care facility ethics committees: New issues in the age of transparency. Human Rights, $34(4)$ : 10.

3. Courtwright A, Brackett S, Cist A, Cornelia Cremens M, Krakauer EL, Robinson EM, 2014, The changing composition of a hospital ethics committee: A tertiary care center's experience. HEC Forum, 26(1): 59-68. doi:10.1007/s10730-013-9218-0

4. Tarzian, ASBH Core Competencies Update Task Force, 2013, Health care ethics consultation: An update on core competencies and emerging standards from the American society for bioethics and humanities' core competencies update task force. The American Journal of Bioethics, 13(2): 3-13. doi: 10.1080/15265161.2012.750388

5. Cohen JS, Erickson JM, 2006, Ethical dilemmas and moral distress in oncology nursing practice. Clinical Journal of Oncology Nursing, 10(6): 775-780. doi: 10.1188/06.cjon.775-780

6. Grady C, Danis M, Soeken KL, O’Donnell P, Taylor C, Farrar A, Ulrich CM, 2008, Does ethics education influence the moral 
action of practicing nurses and social workers? The American Journal of Bioethics, 8(4): 4-11. doi: $10.1080 / 15265160802166017$

7. Oberle K, Hughes D, 2001, Doctors' and nurses' perceptions of ethical problems in end-of-life decisions. Journal of Advanced Nursing, 33(6): 707-715. doi: 10.1046/j.1365-2648.2001.01710.x

8. Woods M, 2005, Nursing ethics education: Are we really delivering the good(s)? Nursing Ethics, 12(1): 5-18. doi: $10.1191 / 0969733005$ ne754oa

9. Zuzelo PR, 2007, Exploring the moral distress of registered nurses. Nursing Ethics, 14(3): 344-359. doi: $10.1177 / 0969733007075870$

10. Redman BK , Fry ST, 2000, Nurses' ethical conflicts: What is really known about them? Nursing Ethics, 7(4): $360-366$. doi:10.1191/096973300667705066

11. MD Anderson, 2017, Quick Facts. Available from: https://www.mdanderson.org/documents/about-md-anderson/about-us/ facts-and-history/quick-facts.pdf

12. Fox E, Myers S, Pearlman RA, 2007, Ethics consultation in United States hospitals: a national survey. The American Journal of Bioethics, 7(2): 13-25. doi: 10.1080/15265160601109085

13. Nilson EG, Acres CA, Tamerin NG, Fins JJ, 2008, Clinical ethics and the quality initiative: a pilot study for the empirical evaluation of ethics case consultation. American College of Medical Quality, 23(5): 356-364. doi: 10.1177/1062860608316729

14. Schneiderman LJ, Gilmer T, Teetzel HD, Dugan DO, Blustein J, Cranford R, Young EW, 2003, Effect of ethics consultations on nonbeneficial life-sustaining treatments in the intensive care setting: A randomized controlled trial. American Medical Association, 290(9): 1166-1172. doi: 10.1001/jama.290.9.1166

15. American Cancer Society I, 2014, Cancer Facts \& Figures 2014 (pp. 70). Atlanta: American Cancer Society.

16. Doane G, Pauly B, Brown H, McPherson G. 2004. Exploring the heart of ethical nursing practice: Implications for ethics education. Nursing Ethics, 11(3): 240-253. doi: 10.1191/0969733004ne692oa

17. Kalaitzidis E, Schmitz K, 2012, A study of an ethics education topic for undergraduate nursing students. Nurse Education Today, 32(1): 111-115. doi: 10.1016/j.nedt.2011.02.006

18. Kearney G, Penque S, 2012, Ethics of everyday decision making. Nursing Management (Harrow), 19(1): 32-36. doi: 10.7748/nm2012.04.19.1.32.c90159 